\title{
Obtenção e utilização de microesferas de parafina para confecção de arcabouços teciduais baseados em cimento de $\alpha$-fosfato tricálcico
}

\section{(Production and use of paraffin microspheres for tissue scaffolds based on $\alpha$-tricalcium phosphate cement)}

\author{
J.L.de M. Machado ${ }^{1}$,L.A dos Santos ${ }^{2}$ \\ Departamento de Materiais/UFRGS, Porto Alegre, Brasil \\ jefmac@gmail.com
}

\begin{abstract}
Resumo
Um dos fatores mais importantes na técnica conhecida por engenharia de tecidos é o crescimento de células em suporte porosos tridimensionais conhecidos por arcabouços. Os arcabouços guiam o crescimento celular e facilitam a formação de tecidos e órgãos funcionais. Cimentos ósseos são materiais desenvolvidos há aproximadamente uma década para aplicações biomédicas. Um cimento deste tipo pode ser preparado misturando um sal de fosfato de cálcio com uma solução aquosa para que se forme uma pasta que possa reagir à temperatura corporal dando lugar a um precipitado que contenha hidroxiapatita. O desenvolvimento de estruturas porosas de cimento de fosfato de cálcio é de grande utilização em engenharia de tecidos, além de outras áreas da traumatologia. O objetivo deste trabalho foi o uso de cimento de $\alpha$-TCP ( $\alpha$-fosfato tricálcico) para obtenção desses arcabouços, através da obtenção e utilização de esferas de parafina como corpos geradores de poros. O $\alpha$-TCP foi sintetizado por resfriamento brusco de seus precursores e, as esferas foram produzidas por suspensão em uma solução aquosa de poli (álcool vinílico) e sulfato de sódio. As quantidades de cada um destes reagentes foram estudadas com relação ao tamanho das esferas formadas. Pela análise de difração de raios X foi detectada a presença de $\beta$-TCP como fase indesejada no processo de síntese do $\alpha$-TCP e de hidroxiapatita deficiente em cálcio após a reação de pega do cimento. Foi analisada a extração da parafina dos arcabouços por utilização de um método térmico. A porosidade dos arcabouços confeccionados com esferas de parafina foi observada por microscopia eletrônica de varredura, mostrando tamanho, forma e interconectividade dos corpos porosos, que se mostrou adequada para o crescimento celular.

Palavras-chave: cimento de fosfato tricálcico, arcabouços, microesferas de parafina.
\end{abstract}

\begin{abstract}
One of the most important factors in tissue engineering is the three-dimensional cells growth in porous support known by scaffolds. The scaffolds guide the cellular growth and facilitate the tissue formation and functional organs. Bone cements have been developed for biomedical applications for a decade approximately. This kind of cement can be prepared mixing a calcium phosphate salt with aqueous solution forming a paste that can react at body temperature generating a hydroxyapatite precipitated. The aim of this work was to use $\alpha-T C P(\alpha$-tricalcium phosphate) cement in order to obtain such scaffolds, with the aid of paraffin spheres as pores generators. These spheres were produced by suspension in a aqueous solution of polyvinylalcohol (PVA) and sodium sulphate $\left(\mathrm{Na}_{2} \mathrm{SO}_{4}\right)$. The amount of each one of the components was related to the size of the formed spheres. The extraction of the paraphyn from the scaffolds was also evaluated. The porosity of the scaffolds produced with paraffin spheres was observed by means of scanning electron microscopy, regarding their size, shape, and interconnectivity, which are important properties of the bone cellular growth process.
\end{abstract}

Keywords: tricalcium phosphate cement, scaffolds, paraffin spheres.

\section{INTRODUÇÃO}

A Engenharia de Tecidos consiste no desenvolvimento e manipulação de moléculas, células, tecidos, ou órgãos crescidos em laboratório para substituir ou apoiar a função de partes de corpo defeituosas ou danificadas. Para que haja a possibilidade de crescer tecido tridimensional complexo, literalmente reproduzindo a forma e função do tecido humano, faz-se necessário o uso de um suporte que permita o crescimento celular, sendo este suporte chamado de arcabouço [1]. Para cumprir essa função o arcabouço deve possuir propriedades como biocompatibilidade, alta porosidade e tamanho e formato de poros adequado para permitir o crescimento de tecidos (no caso de tecidos ósseos esse tamanho é entre 150 e $250 \mu \mathrm{m}$ ). Deve possuir taxa de degradação adequada, fazendo com que haja perda de resistência mecânica gradual, para que os tecidos substituam o arcabouço nem muito lentamente nem muito rapidamente.

Um cimento de fosfato de cálcio (CFC) pode ser 
preparado misturando um sal de fosfato de cálcio com água ou com uma solução aquosa para que se forme uma pasta que possa reagir à temperatura ambiente ou corporal dando lugar a um precipitado que contenha um ou mais fosfato de cálcio, ocorrendo a pega pelo intercruzamento dos cristais deste precipitado [2]. Apesar da existência de diversos sistemas de CFC estudados, os baseados no alfa-fosfato tricálcico $(\alpha-\mathrm{TCP})$ são de especial interesse em função da obtenção durante a reação de pega de uma fase de hidroxiapatita deficiente em cálcio, similar à hidroxiapatita óssea:

$$
\alpha-\mathrm{Ca}_{3}\left(\mathrm{PO}_{4}\right)_{2}+\mathrm{H}_{2} \mathrm{O} \rightarrow \mathrm{Ca}_{9}\left(\mathrm{HPO}_{4}\right)\left(\mathrm{PO}_{4}\right)_{5} \mathrm{OH}
$$

A hidroxiapatita favorece o crescimento ósseo para os locais em que ela se encontra, estabelecendo ligações de natureza química entre a hidroxiapatita e o tecido ósseo (bioativo), permitindo a proliferação de fibroblastos, osteoblastos e outras células ósseas, sendo que as células não distinguem entre a hidroxiapatita e a superfície óssea, o que indica a grande similaridade química superficial [3].

Inúmeros processos são atualmente utilizados para produzir cerâmicas porosas [4]. As técnicas mais simples se baseiam na incorporação de uma segunda fase orgânica na composição do material cerâmico, em proporções e tamanho controlados, que após sua eliminação deixam vazios de mesmo tamanho. A incorporação de uma segunda fase orgânica na composição do material cerâmico, em proporções e tamanho controlados, permite o controle do tamanho de poros pela eliminação posterior da fase orgânica, com a sinterização. Após a sinterização o corpo final apresenta poros com o mesmo tamanho das fases orgânicas inseridas na mistura. Para conseguir uma maior resolução para os arcabouços com poros esféricos interconectados bem controlados, esferas de parafina fabricadas por um método de dispersão podem ser incorporadas ao cimento.

O objetivo do trabalho foi a obtenção e caracterização de cimento de fosfato de cálcio poroso, com potencial uso como suportes tridimensionais para a engenharia de tecidos, com uma matriz baseada em cimento de $\alpha$-fosfato tricálcico, utilizando como meio gerador de poros microesferas de parafina.

\section{MATERIAIS E MÉTODOS}

\section{Obtenção de cimento de $\alpha-T C P$}

O cimento de $\alpha$-fosfato tricálcico ( $\alpha$-TCP) foi sintetizado em laboratório utilizando-se o carbonato de cálcio $\left(\mathrm{CaCO}_{3}\right)$ (Nuclear) e o pirofosfato de cálcio $\left(\gamma-\mathrm{Ca}_{2} \mathrm{P}_{2} \mathrm{O}_{7}\right)$. A homogeneização inicial entre os precursores foi realizada a seco em moinho de bolas de alumina por um período de tempo de $1 \mathrm{~h}$. O processo de calcinação permitiu a reação dos dois precursores químicos, a fase gama do pirofosfato de cálcio e carbonato de cálcio, que foram mantidos em forno tipo mufla a temperatura de $1300{ }^{\circ} \mathrm{C}$ por $5 \mathrm{~h}$, seguido de resfriamento brusco. $\mathrm{O} \alpha$-TCP após resfriamento foi desagregado manualmente com almofariz e pistilo de porcelana. A moagem a úmido foi feita utilizando álcool etílico absoluto $\left(\mathrm{CH}_{3} \mathrm{CH}_{2} \mathrm{OH}\right)$ por $2 \mathrm{~h}$. A composição resultante foi alocada em um béquer, onde permaneceu $72 \mathrm{~h}$ em estufa a $90{ }^{\circ} \mathrm{C}$ para promover a evaporação total do álcool. Após a moagem em álcool, o $\alpha$-TCP passa a se chamar cimento. A fração líquida do cimento foi formulada com o objetivo de se obter uma solução aquosa aceleradora da reação de presa do cimento, semelhante à composição utilizada na literatura para mistura de cimentos de $\alpha$-TCP. A formulação mais difundida para a fração líquida corresponde a uma solução de $2,5 \%$ de hidrogenofosfato disódico $\left(\mathrm{Na}_{2} \mathrm{HPO}_{4}\right)$ em água destilada e deionizada, sendo esta a utilizada.

\section{Obtenção de esferas de parafinas}

Para o estudo e obtenção de parafina na forma de microesferas utilizou-se um béquer com capacidade para $1 \mathrm{~L}$ contendo $500 \mathrm{~mL}$ de água deionizada, adições de 0,1 , $0,2,0,4,0,8$ e 1,6\% de poli (álcool vinílico) (PVA) (Kuraray Poval), e adições de $0,0,2,0,5,1,0$ e 2,0\% de sulfato de sódio $\left(\mathrm{Na}_{2} \mathrm{SO}_{4}\right)$ (Synth). Esta solução foi aquecida a $100{ }^{\circ} \mathrm{C}$ e nela foi adicionada a parafina comercial (Petrobrás) e aguardada sua total fusão $\left(67^{\circ} \mathrm{C}\right)$. Colocou-se o sistema sob agitação mecânica a $400 \mathrm{rpm}$ durante aproximadamente $10 \mathrm{~min}$ para a formação de uma espuma consistente, e então foi desligado o aquecimento e feito um resfriamento rápido com a adição de água fria (aproximadamente $5{ }^{\circ} \mathrm{C}$ ). As esferas foram então colocadas em uma torre de peneiras, lavadas com água destilada e separadas em faixas de granulometrias. As esferas foram lavadas com água destilada e deionizada, secas à temperatura ambiente e armazenadas em dessecador.

\section{Obtenção e caracterização dos arcabouços}

Os arcabouços foram confeccionados homogeneizandose manualmente as esferas de parafina juntamente com o cimento de $\alpha$-TCP e só então adicionado a fase líquida. A fase líquida foi adicionada na proporção de $1 \mathrm{~mL}$ para cada $1 \mathrm{~g}$ de cimento. As esferas de parafina foram adicionadas nas seguintes porcentagens em volume: $57,63,66,70$ e $72 \%$ (densidade da parafina $=0,89 \mathrm{~g} / \mathrm{cm}^{3}$, densidade do cimento $=2,35 \mathrm{~g} / \mathrm{cm}^{3}$ ). A pasta formada foi vazada em moldes de silicone e os corpos-de-prova foram desmoldados após 24 $\mathrm{h}$ de cura e então submetidos a um tratamento térmico a diferentes temperaturas e taxas de aquecimento para extração da parafina.

As análises de TGA da parafina foram feitas no aparelho TA Instr. 2050 , na faixa de $30{ }^{\circ} \mathrm{C}$ a $1000{ }^{\circ} \mathrm{C}$ com taxa de aquecimento $20{ }^{\circ} \mathrm{C} / \mathrm{min}$, para verificação do comportamento de degradação térmica da parafina. A avaliação da composição de fases dos materiais obtidos e após tratamentos térmicos foi feita em difratômetro de raios X Phillips X’Pert MPD. A análise por microscopia teve como objetivo auxiliar as investigações das características microestruturais. O microscópio eletrônico de varredura utilizado foi JEOL JSM-6060. 


\section{RESULTADOS E DISCUSSÃO}

\section{Obtenção de cimento de $\alpha$-TCP}

O $\alpha$-TCP obtido pelo método empregado na síntese foi composto de $\alpha$-TCP como fase majoritária, acrescida de uma quantidade de $\beta$-TCP como fase indesejável, como demonstrado pela análise qualitativa de difração de raios X. Na Fig. 1 é apresentado o difratograma do material obtido.

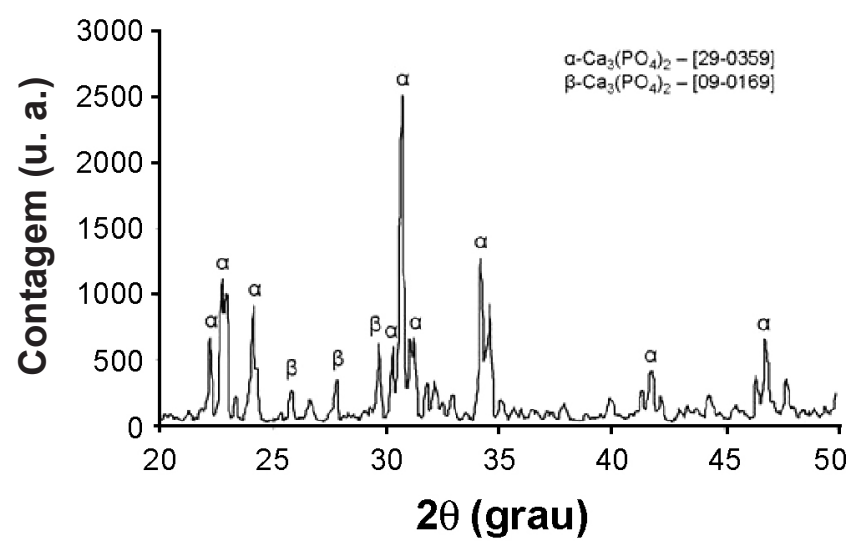

Figura 1: Difratograma de raiso $\mathrm{X}$ do cimento de fosfato tricálcico obtido pela reação entre $\gamma-\mathrm{Ca}_{2} \mathrm{P}_{2} \mathrm{O}_{7}$ e $\mathrm{CaCO}_{3}$ a $1300{ }^{\circ} \mathrm{C}$ durante $5 \mathrm{~h}$, seguido de resfriamento brusco.

[Figure 1: X-ray diffraction pattern of the tricalcium phosphate cement produced by the reaction between $\gamma-\mathrm{Ca}_{2} \mathrm{P}_{2} \mathrm{O}_{7}$ and $\mathrm{CaCO}_{3}$ at $1300{ }^{\circ} \mathrm{C}$, during $5 \mathrm{~h}$, followed by rapid cooling.]

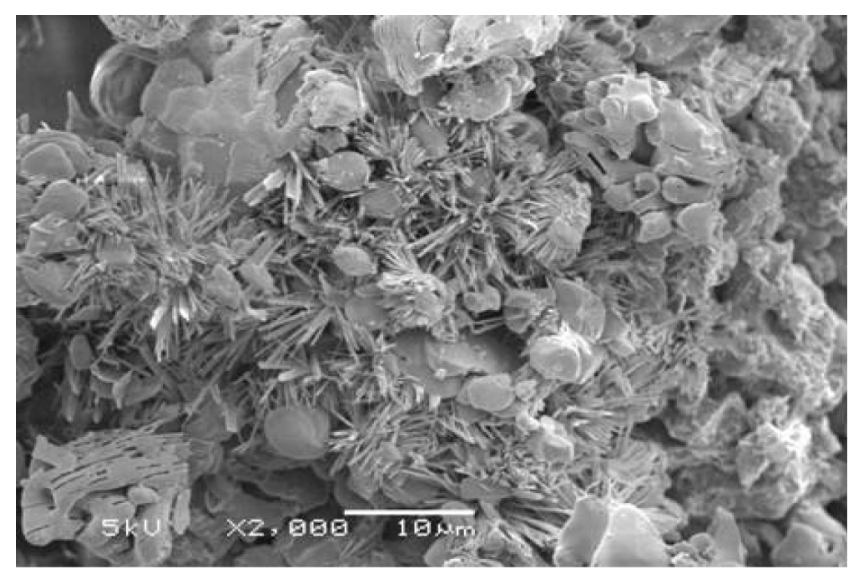

Figura 2: Fotomicrografia obtida por microscopia eletrônica de varredura da amostra de cimento reagido com relação líquido/pó de $0,4 \mathrm{~mL} / \mathrm{g}$.

[Figure 2: SEM micrograph of the reacted cement with liquid-topowder ratio of $0.4 \mathrm{~mL} / \mathrm{g}$.]

A presença de $\beta$-TCP como fase indesejada no processo de síntese do $\alpha$-TCP tem sido reportada [5]. Atualmente ainda não são conhecidos registros sobre a obtenção de $\alpha$-TCP puro, independentemente do método de síntese utilizado, sendo a etapa de resfriamento brusco a etapa crítica neste processo [6]. A transformação $\beta$-TCP em $\alpha$-TCP é lenta e reversível, o que exige, para a obtenção do $\alpha$-TCP de maior pureza, a utilização de tempos de patamar elevados a temperaturas superiores a $1200{ }^{\circ} \mathrm{C}$, visando assegurar a máxima conversão, e resfriamento brusco para preservar a fase $\alpha$-TCP à temperatura ambiente.

O cimento foi homogeneizado com a fração líquida tendo uma relação líquido/pó de $0,4 \mathrm{~mL} / \mathrm{g}$, deixando a pasta por $24 \mathrm{~h}$ à temperatura ambiente. Constatou-se a presença da fase hidroxiapatita deficiente em cálcio $\left(\mathrm{Ca}_{9}\left(\mathrm{HPO}_{4}\right)\left(\mathrm{PO}_{4}\right)_{5} \mathrm{OH}\right)$. A micrografia da superfície de fratura do cimento reagido é apresentada na Fig. 2. O aparecimento de agulhas ou placas petalóides é característico dos cimentos de fosfato de cálcio baseados no $\alpha$-TCP $[2,7,8]$. É pelo intercruzamento destes cristais que ocorre o aumento da resistência mecânica do material [2].

\section{Obtenção de esferas de parafinas}

As esferas de parafina foram confeccionadas com intuito de obter corpos orgânicos que poderiam, após calcinação, proporcionar a formação de poros de formato, tamanho e distribuição de tamanho controlados. Além disso, é importante que haja a interconexão desses poros para possibilitar o crescimento tecidual. A parafina foi escolhida por ser um material orgânico de baixo ponto de fusão, o que possibilita uma facilidade no processamento; ter inércia química, fazendo com que não haja nenhuma reação com o cimento ou a fase líquida; ser de baixo custo. Para obtenção de esferas de parafina foram feitos testes iniciais baseados na literatura [9] com a utilização somente de álcool polivinílico na solução de agitação. Não foram obtidos resultados satisfatórios, pois parte das esferas formadas ficaram com um tamanho acima do esperado e unidas em aglomerados. A partir do trabalho de Mizutani e colaboradores [10], que utilizou $\mathrm{Na}_{2} \mathrm{SO}_{4}$ na obtenção de esferas de poli (ácido l-lático) (PLLA), determinou-se que este também seria importante na obtenção de esferas de parafina. A espuma formada sob a agitação da solução de PVA mais $\mathrm{Na}_{2} \mathrm{SO}_{4}$ se tornou mais espessa visualmente, com maior estabilidade, o que permitiu a formação de esferas de parafina de menor tamanho, sem estarem aglomeradas e sem a formação de pedaços disformes. Em uma solução de PVA ocorre uma precipitação do mesmo depois da adição de um sal que contenha íons sulfatos, fosfatos, carbonatos, sódio e ou potássio, sendo que estes funcionam como um agente coagulante [10]. Há uma alta concentração de PVA e do sal na região de interface entre a solução e o material com o qual se deseja fazer esferas, formando uma membrana de PVA ao redor do material. A quantidade de PVA utilizada na formação de esferas, tanto de poli(ácido 1-lático) (PLLA), poli(ácido glicólico) (PGA) quanto de parafina, varia na literatura. Shum e colaboradores [9] utilizaram 2,5 g de PVA em $500 \mathrm{~mL}$ de água destilada, a uma temperatura de $70{ }^{\circ} \mathrm{C}$ 
não mencionado a velocidade de agitação, para esferas de parafina. Ma e colaboradores [11] também utilizaram 2,5 g de PVA, mas para esferas de PLLA. Foi utilizado $0,03 \%$ em peso de PVA em uma solução de $500 \mathrm{~mL}$ de água destilada a temperatura ambiente com uma agitação entre 300 e 700 rpm, também para PLLA, mas também utilizando uma concentração de $0,15 \mathrm{~mol} / \mathrm{L}$ de um agente coagulante [10]. Considerando que o tipo de agente coagulante utilizado modificou a forma do corpo formado [10], e que o agente coagulante usado para confecção de corpos esféricos foi $\mathrm{O} \mathrm{Na}_{2} \mathrm{SO}_{4}$, este foi escolhido para a produção de esferas de parafina. A partir desses resultados, foram feitos estudos preliminares para saber qual a quantidades de PVA e $\mathrm{Na}_{2} \mathrm{SO}_{4}$ seriam utilizados. Os resultados podem ser visualizados na Fig. 3 .

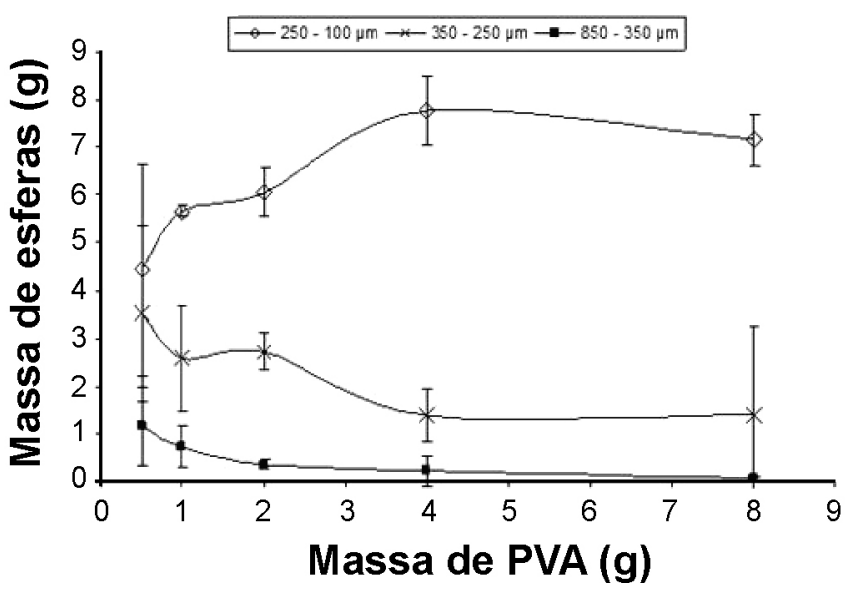

Figura 3: Variação da massa de esferas de parafina formada pela quantidade de PVA utilizada na solução.

[Figure 3: Variation of the paraffin spheres mass as a function of PVA amount in the solution.]

Considerando que o tamanho de poro ideal para o crescimento de tecido ósseo é acima de $150 \mu \mathrm{m}$ [12], a faixa granulométrica adotada foi a de 100 a $250 \mu \mathrm{m}$. Analisando o gráfico da Fig. 3, há maior formação de esferas nessa faixa granulométrica para uma solução contendo $4 \mathrm{~g}$ de PVA. Resultados semelhantes foram obtidos para a variação da quantidade de $\mathrm{Na}_{2} \mathrm{SO}_{4}$, ficando o valor ideal em torno de $5 \mathrm{~g}$. Estes foram, então, os valores adotados para a produção das esferas de parafina. A distribuição de tamanho fez-se através da separação em peneiras. As esferas utilizadas foram da faixa de 100 a $250 \mu \mathrm{m}$.

\section{Obtenção e caracterização dos arcabouços}

A análise termogravimétrica da parafina mostrou o pico de degradação a aproximadamente $370{ }^{\circ} \mathrm{C}$, mas a degradação completa ocorre um pouco antes de $600{ }^{\circ} \mathrm{C}$. Tendo em vista a baixa temperatura de degradação, não é necessário o estudo de outros materiais como agentes porogênicos, ou mesmo parafinas de menor tamanho de cadeia, eventualmente mais custosos do que a parafina comercial, de custo extremamente baixo e de fácil acesso.

$\mathrm{O}$ fato do $\alpha$-TCP ser metaestável à temperatura ambiente, e o fato da hidroxiapatita formada na reação de cura do cimento ser deficiente em cálcio, teve-se que se tomar cuidado na escolha da temperatura de extração da parafina. Uma temperatura muito elevada favoreceria o aparecimento de novas fases na estrutura, o que poderia ser um inconveniente, pois não teríamos mais um fosfato de cálcio absorvível, sendo este fundamental para a obtenção de um suporte temporário para crescimento celular.

Um estudo da modificação de fases do cimento após a cura com um aumento da temperatura se fez necessário. Para isso calcinou-se o cimento curado, isento de parafina, em diferentes temperaturas, inicialmente a $600{ }^{\circ} \mathrm{C}$, pois era a temperatura na qual, segundo a análise TGA, ocorria a total degradação da parafina. A análise de difração do raios $\mathrm{X}$ do cimento calcinado a 600,700 e $800{ }^{\circ} \mathrm{C}$, com uma taxa de $10^{\circ} \mathrm{C} / \mathrm{min}$ e um patamar de $1 \mathrm{~h}$ pode ser vista na Fig. 4. O difratograma praticamente não revela diferença nas fases entre o cimento analisado logo após a cura, exceto uma diminuição nos picos da fase $\alpha$, o que pode indicar que essa fase está se transformando na fase $\beta$, sendo esta mais estável nesta temperatura. A fase $\beta$ do fosfato tricálcico também é absorvível, mas a uma taxa mais lenta que a fase $\alpha$, devido a um maior empacotamento da fase $\beta$. Com isso o tempo que o arcabouço teria para ser absorvido poderia ser modificado. Com o aumento da temperatura de calcinação para $700{ }^{\circ} \mathrm{C}$, mantendo as mesmas condições de queima, observou-se uma mudança brusca na composição das fases. Ocorreu praticamente, um desaparecimento da fase $\alpha$, e uma diminuição considerável da fase hidroxiapatita, para um aumento da fase $\beta$. Pelos resultados desse difratograma ficou estabelecido que a extração da parafina deve ser

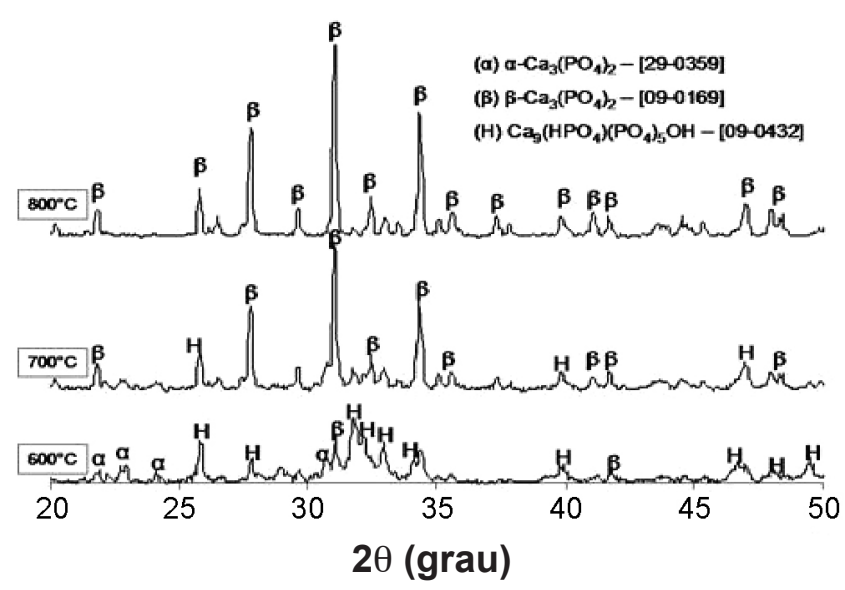

Figura 4: Difratograma de raios $\mathrm{X}$ do cimento de fosfato tricálcico após queima a 600,700 e $800{ }^{\circ} \mathrm{C}$.

[Figure 4: X-ray diffraction patterns of tricalcium phosphate cement after calcination at 600,700 , and $800^{\circ} \mathrm{C}$.] 
feita no máximo a temperatura de $600{ }^{\circ} \mathrm{C}$, pois com uma temperatura um pouco maior ocorreria a modificação do material do arcabouço. Não foram encontrados dados de literatura que mostrassem comportamento similar, sendo o estudo da influência da temperatura nas fases cristalinas ainda um aspecto não estudado dos cimentos de fosfato de cálcio. Tais estudos poderão ser úteis na obtenção de materiais de fosfato de cálcio contendo mais de uma fase cristalina ( $\alpha$-TCP, $\beta$-TCP, hidroxiapatita) e com diferentes cristalinidades, e, portanto, com solubilidades e comportamentos in vivo diferenciados, o que pode ser útil em aplicações tais como a liberação controlada de drogas, preenchimento de grandes cavidades, etc. Além disso, o aumento da cristalinidade e da temperatura de calcinação pode resultar em valores de resistência mecânica mais elevados e mais próximos dos tecidos que se pretende substituir. Para fins de comparação, o difratograma da queima do cimento a temperatura de 800 ${ }^{\circ} \mathrm{C}$ mostra a total predominância da fase $\beta$, modificando totalmente o material da estrutura do arcabouço.

A extração de ceras de corpos cerâmicos deve ser feita a uma taxa de aquecimento mais baixa possível [12]. A extração de ligantes é o passo mais crítico na moldagem por injeção, onde a parafina é muito usada como ligante, sendo que a sua quantidade pode chegar a $50 \%$ em volume [14]. A parafina deve ser removida lentamente, em um processo que requer a gradual formação de canais ao longo da peça. Estes canais permitem que a parafina saia da peça sem causar o seu colapso [15]. O diâmetro dos canais depende do tamanho das partículas do pó e da porosidade da peça e sua forma é altamente variável dentro da peça injetada. Os canais têm um alto nível de interconectividade e são tortuosos, de tal forma que o ligante fluido percorre uma distância muito maior que a espessura da peça cerâmica [15]. Como no cimento, a reação de cura une as partículas através de um ancoramento provocado pelas agulhas de CDHA e, como todo cimento de pega hidráulica há a formação de poros capilares que representam a parte do volume total não preenchida pelos produtos da hidratação, supomos que estes poros acabam formando microcanais, sendo responsáveis por grande parte do fluxo de parafina líquida. Nestes microcanais a parafina acabava fluindo para fora do corpo sem danificá-lo, ao mesmo tempo em que era degradada. Uma outra forma de se fazer a queima para extração da parafina sem danificar a estrutura do cimento foi utilizar um pré-tratamento do corpo de prova em uma estufa a $100{ }^{\circ} \mathrm{C}$ durante $\sim 2 \mathrm{~h}$. Este tratamento era realizado com o auxílio de um papel absorvente que ficava em contato com o corpo de prova. Como a temperatura de fusão da parafina é em torno de $70{ }^{\circ} \mathrm{C}$, essa temperatura era suficiente para a fusão da parafina e esta ser absorvida pelo papel na medida em que fluía para fora do corpo de prova. Desta maneira, restava pouca parafina no corpo de prova, e os microcanais conseguiam eliminar a parafina residual e seus subprodutos de composição sem causar um aumento de pressão exagerado dentro dos poros, que acabaria colapsando o corpo de prova. É reportada uma variante da extração térmica chamada de wicking, que é um processo no qual um ligante líquido, com baixa viscosidade, é "sugado" por forças capilares em um meio poroso que envolve a peça cerâmica $[13,15]$. É o processo conhecido como fluxo capilar em leito poroso ("wicking"). O fluxo capilar do líquido através do meio poroso que envolve a peça impede que se forme uma descontinuidade líquido-vapor na superfície do corpo, que poderia provocar a formação de defeitos na peça. Era possível desta forma, colocar o corpo de prova no forno a uma taxa mais alta sem a destruição de estrutura. A taxa usada foi $10^{\circ} \mathrm{C} / \mathrm{min}$ e os corpos mantiveram sua estrutura de poros intacta. Para a remoção de resíduos carbonáceos (pseudografíticos e cadeias com ligações cruzadas) [16], provenientes da extração térmica, os corpos-deprova foram imersos em peróxido de hidrogênio, de modo a haver uma quantidade de oxigênio na atmosfera e adsorvido nas paredes do corpo, e fez novamente o aquecimento. A quantidade ideal de esferas adicionadas está ligada à formação de uma camada mínima de cimento entre as esferas, de forma que elas possam entrar em contato umas com as outras e assim, após retirada da parafina, serem formadas interconexões entre os poros oriundos das esferas de parafina.

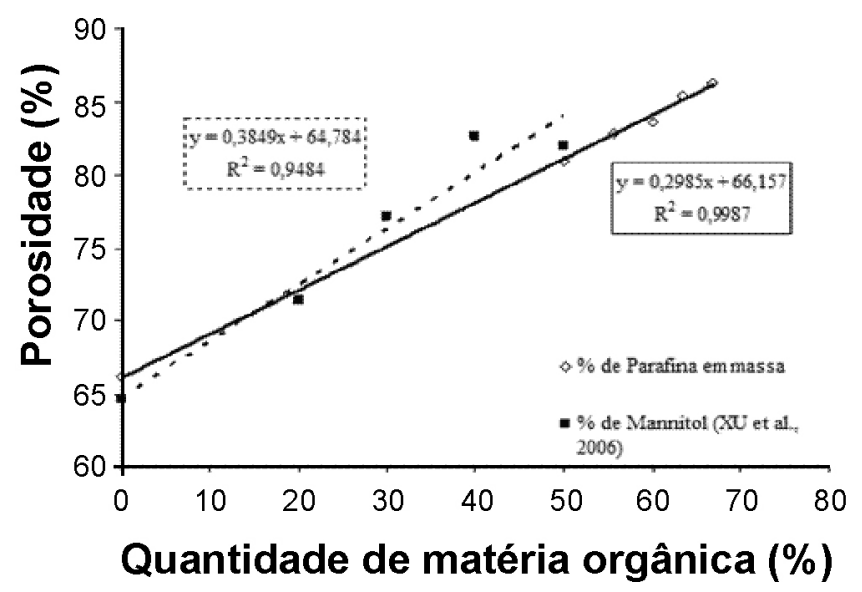

Figura 5: Porosidade em função da quantidade de parafina utilizada na confecção dos arcabouços.

[Figure 5: Porosity as a function of paraffin content used to produce scaffolds.]

Os valores de porosidade dos arcabouços em relação à quantidade de parafina podem ser vistos na Fig. 5. Os valores foram comparados com valores reportados [17] utilizando cimento de fosfato tetracálcico (TTCP) e Mannitol $\left(\mathrm{CH}_{2} \mathrm{OH}[\mathrm{CHOH}]_{4} \mathrm{CH}_{2} \mathrm{OH}\right)$ como gerador de poros, nas quantidades $0,20,30,40$ e $50 \%$ em peso.

Os resultados são bastante similares, mostrando a linearidade com que cresce a porosidade na medida em que se adiciona matéria orgânica para a obtenção de poros. A razão pó-líquido utilizada em [17] foi de 2:1, ou seja, $2 \mathrm{~g}$ de pó para $1 \mathrm{~g}$ do líquido, obtendo uma porosidade 
$64,8 \%$, ligeiramente menor que a do material utilizada neste trabalho $(66,2 \%)$, no qual foi utilizada uma razão 1:1. Os valores de $\mathrm{R}^{2}$ comprovam a linearidade dessas curvas, com valores maiores que 0,9. A inclinação das retas é menor do que 1 , mostrando que é necessária uma quantidade maior de matéria orgânica para que se tenha um pequeno aumento na porosidade.

Uma fotomicrografia do arcabouço formado pode ser vista na Fig. 6. Ressalta-se a forma esférica dos poros e a interconectividade. Não foram encontrados dados na literatura que demonstrem a quantidade necessária de esferas para obter-se interconectividade. A quantidade de esferas adicionadas está ligada à formação de uma camada mínima de cimento entre as esferas, de forma que elas possam entrar em contato umas com as outras e, assim, após retirada da parafina, serem formadas interconexões entre os poros oriundos das esferas de parafina.

A fixação da quantidade de cimento e fase líquida teve como objetivo não variar a resistência mecânica da matriz do cimento após a pega. Embora a quantidade de fase líquida seja relativamente grande em relação ao cimento, visto que a quantidade mínima de fase líquida para formar uma pasta é de $0,4 \mathrm{~mL} / \mathrm{g}$, isto era necessário para dar molhabilidade às esferas de parafina que entraram na composição, e $1 \mathrm{~mL}$ era o mínimo necessário para a formar uma pasta homogênea com a composição de 2,0 g de parafina para $1,0 \mathrm{~g}$ de cimento. A resistência mecânica dos arcabouços foi extremamente reduzida, pois além do fato do da matriz de cimento perder resistência com o aumento da fase líquida, a quantidade de poros formada reduziu a resistência mecânica dos arcabouços ao ponto de não ser possível medi-la em máquina universal de ensaios. Os arcabouços tinham a resistência mínima suficiente para o manuseio dos mesmos, o que de certo modo já é suficiente, pois os arcabouços deverão ganhar resistência mecânica com a proliferação de osteoblastos ao formar o tecido ósseo, e isto se dá de modo extracorpóreo, in vitro, sem grandes solicitações mecânicas.

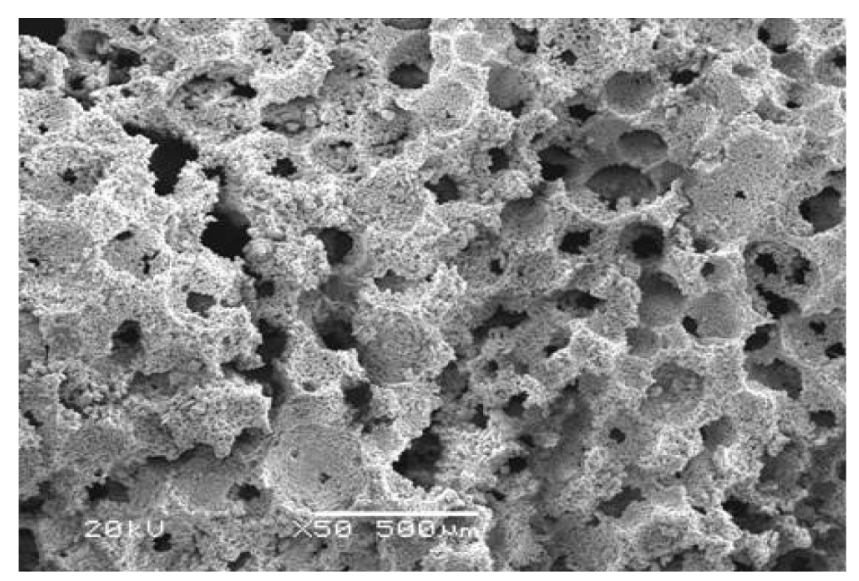

Figura 6: Fotomicrografia de MEV do arcabouço confeccionado com $82 \%$ de parafina.

[Figure 6: SEM micrograph of scaffolds produced with $82 \%$ of paraphyn.]

\section{CONCLUSÕES}

Foi obtido e caracterizado o cimento de fosfato de cálcio poroso, com potencial uso como suportes tridimensionais para a engenharia de tecidos, a partir de cimento ósseo de fosfato de cálcio, e microesferas de parafina como corpo gerador de poros. Este é um método inovador e o desenvolvimento deste trabalho permitiu a obtenção de uma composição de cimento de fosfato de cálcio com base no $\alpha$-fosfato tricálcico, cuja reação de cura ocasionou a precipitação de uma hidroxiapatita deficiente em cálcio $\left(\mathrm{Ca}_{9}\left(\mathrm{HPO}_{4}\right)\left(\mathrm{PO}_{4}\right)_{5} \mathrm{OH}\right)$, além da fase $\beta$-TCP e a manutenção da fase $\alpha$-TCP não reagida. Através da microscopia ele-trônica de varredura foi observada a estrutura acicular característica dos cimentos de fosfatos de cálcio baseados em $\alpha$-TCP. Foram obtidas esferas de parafina com diâmetro na faixa de micrômetros utilizando-se método reportado na literatura, e estas foram eficazes na fabricação de corpos porosos após a cura do cimento e sua posterior extração por meio de um método térmico. A temperatura para a extração da parafina do cimento foi determinada em $600{ }^{\circ} \mathrm{C}$, não ocorrendo mudança significativa das fases do cimento. Os arcabouços obtidos com esferas de parafina tiveram poros com formato esférico e interconectados.

\section{REFERÊNCIAS}

[1] P. X. Ma, R. Langer, Mater. Res. Soc., PA, EUA (1995) 99.

[2] S. E. Gruninger, C. Siew, L. C. Chow, A. O'Young, N. K. Tsao, W. E. Brown, J. Dentistry Res. 63 (1984) 200.

[3] L. L. Hench, Anal. Quim. 93, 1 (1997) S3.

[4] P. Sepúlveda, Am. Ceram. Soc. Bull. 76, 10 (1997) 61.

[5] O. Bermudez, M. G. Boltong, F. C. M. Driessens, J. A. Planell, J. Mater. Sci.: Mater. Medic. 5 (1994) 160.

[6] S. Raynaud, E. Champion, D. Bernache-Assollant, P. Thomas, Biomater. 23 (2002) 1065.

[7] D. Yu, J. Wong, Y. Matsuda, J. Fox, W. I. Higuchi, M. Otsuka, J. Pharm. Sci. 81, 6 (1992) 529.

[8] F. C. M. Driessens, E. Fernández, M. P. Ginebra, M. G. Boltong, J. A. Planell, Anal. Quim. 93, 1 (1997) S38. [9] A. W. T. Shum, J. Li, A. F. T. Mak, Polymer Degradation Stability 87 (2005) 487.

[10] Y. Mizutani, M. Hattori, M. Okuyama, T. Kasuga, M. Nogami, Polymer 46 (2005) 3789.

[11] P. X. Ma, in Encyclopedia of Polymer Science and Technology, $3^{\text {rd }}$ Ed., J. I. Kroschwitz, Ed. John Wiley \& Sons, NJ, EUA (2004).

[12] K. J. L. Burg, S. Porter, J. F. Kellan, Biomater. 21 (2000) 2347.

[13] J. E. Zorzi, Tese de Doutorado, UFRGS, Porto Alegre, RS (2001) 149.

[14] M. Trunec, J. Cihlár, J. Eur. Ceram. Soc. 17 (1997) 203. 
[15] B.C. Mutsuddy, R. G. Ford, Ceramic Injection Molding, Chapman \& Hall, London, Inglaterra (1995).

[16] J. Lewis, Ann. Rev. Mater. Sci. 27 (1997) 147.
[17] H. H. K. Xu, M. D. Weir, E. F. Burguera, A. M. Fraser, Biomater. 27, 24 (2006) 4279.

(Rec, 05/08/2008, Ac. 24/10/2008) 